\title{
Hypocalcemia: the quest for the cause of a major biochemical feature of COVID-19
}

\author{
Luigi di Filippo $^{1}$ - Anna Maria Formenti ${ }^{1}$ Andrea Giustina ${ }^{1}{ }^{1}$
}

Received: 4 October 2020 / Accepted: 13 October 2020 / Published online: 22 October 2020

(c) Springer Science+Business Media, LLC, part of Springer Nature 2020

\section{Dear Editor,}

We read with interest the Letter "Mechanistic basis and therapeutic relevance of hypocalcemia during severe COVID-19 infection" ${ }^{\prime \prime}$ written by Singh et al. [1]. We thank the authors for their relevant contribution to the topic of hypocalcemia in COVID-19 and for their kind comments to our work [2], which seminally reported a high prevalence of this biochemical alteration in hospitalized COVID-19 [3]. Following our report several other contributions confirmed and corroborated our finding [4] as one of the most frequent endocrine and metabolic aspects of the pandemic [5].

Therefore, since hypocalcemia is now consistently indicated as a major biochemical feature in COVID-19 with relevant clinical impact, all the works that contribute to a better understanding of its underlying mechanisms and clinical implications may be relevant to the management of patients with COVID-19.

The authors previously reported elevated levels of unbound and unsaturated fatty acids (UFA) in COVID-19, particularly in severe patients. UFA are known to have proinflammatory effects and to induce cytokine storm and multisystem organ failure in severe acute pancreatitis. Interestingly, UFA can bind calcium and albumin causing hypocalcemia and hypoalbuminemia, typically reported in COVID-19 patients [1].

We agree with the authors that a similar mechanism can be hypothesized to occur also in COVID-19, with increased levels of UFA contributing to hypocalcemia particularly in severe COVID-19 patients and representing a relevant potential new target of intervention [1].

Andrea Giustina

Giustina.andrea@hsr.it

1 Institute of Endocrine and Metabolic Sciences, Vita Salute San Raffaele University and IRCCS San Raffaele Hospital, Milano, Italy
However, it is likely that one single mechanism could not explain a so widespread phenomenon in a quite heterogenous population with different degree of severity and multifaced clinical background and manifestations [6]. In fact, besides the calcium dependent viral mechanism of action and the enhanced cellular permeability to calcium ions we previously hypothesized that hypovitaminosis D could be a predisposing factor to hypocalcemia [2]. Whereas we agree with the authors that chronic lack of vitamin $\mathrm{D}$ is not likely to be the only causative factor of acute hypocalcemia [7], high prevalence of vitamin D deficiency in COVID-19 patients was reported by several studies [8]. Since vitamin D is involved in immunocompetence both with regard to innate and adaptive immunity [9], it has been hypothesized that vitamin D deficiency may predispose to SARS-CoV-2 infection and lower levels of vitamin D could be related to increased COVID-19 severity [8]. Chronic vitamin D deficiency is known to alter calcium metabolism and infection by SARSCoV-2 could predispose to/exacerbate hypocalcemia occurrence in COVID-19 patients, particularly in severe patients.

Interestingly, the authors of this letter also pointed out that early correction of hypocalcemia may be a therapeutic target to improve COVID-19 outcomes, and not just a predictor of severity [1]. We agree on this concept. In fact, to date, several clinical studies confirmed our initial findings that hypocalcemia may be a relevant risk factors for hospitalization [2], but also for ICU admission and worse disease outcomes in COVID-19 patients [8]. Moreover, hypocalcemia per se when severe can complicate the cardiovascular and neurological picture of COVID-19 [2]. However, no data yet were published regarding the effect of calcium supplementation on COVID-19 hypocalcemic patients outcomes.

Therefore, currently it can only be suggested that calcium levels should always be checked at hospital admission, carefully monitored and replaced as clinically indicated in COVID-19 patients. Further studies are needed to clarify if 
calcium (and vitamin D) supplementation may have a relevant clinical impact in the natural history of COVID-19.

\section{Compliance with ethical standards}

Conflict of interest The authors declare that they have no conflict of interest.

Publisher's note Springer Nature remains neutral with regard to jurisdictional claims in published maps and institutional affiliations.

\section{References}

1. V.P. Singh, B. Khatua, B. El-Kurdi, C. Rood, Mechanistic basis and therapeutic relevance of hypocalcemia during severe COVID19 infection. Endocrine (2020).

2. L. Di Filippo, A.M. Formenti, P. Rovere-Querini, M. Carlucci, C. Conte, F. Ciceri, A. Zangrillo, A. Giustina, Hypocalcemia is highly prevalent and predicts hospitalization in patients with COVID-19. Endocrine 68(Jun), 475-478 (2020). https://doi.org/10.1007/ s12020-020-02383-5.

3. S. Bossoni, L. Chiesa, A. Giustina, Severe hypocalcemia in a thyroidectomized woman with Covid-19 infection. Endocrine 68 (May), 253-254 (2020). https://doi.org/10.1007/s12020-02002326-0.
4. M. Marazuela, A. Giustina, M. Puig-Domingo, Endocrine and metabolic aspects of the COVID-19 pandemic. Rev. Endocr. Metab. Disord. 9(Jul), 1-13 (2020). https://doi.org/10.1007/ s11154-020-09569-2.

5. M. Puig-Domingo, M. Marazuela, A. Giustina, COVID-19 and endocrine diseases. A statement from the European Society of Endocrinology. Endocrine 68(Apr), 2-5 (2020). https://doi.org/10. 1007/s12020-020-02294-5.

6. A.M. Formenti, E. Pedone, L. di Filippo, F.M. Ulivieri, A. Giustina. Are women with osteoporosis treated with denosumab at risk of severe COVID-19? Endocrine 20(Sep), 1-3. https://doi.org/10. 1007/s12020-020-02500-4.

7. A. Giustina, R.A. Adler, N. Binkley, R. Bouillon, P.R. Ebeling, M. Lazaretti-Castro, C. Marcocci, R. Rizzoli, C.T. Sempos, J.P. Bilezikian, Controversies in vitamin D: summary statement from an international conference. J. Clin. Endocrinol. Metab. 104(Feb 1), 234-240 (2019). https://doi.org/10.1210/jc.2018-01414.

8. J.P. Bilezikian, D. Bikle, M. Hewison, M. Lazaretti-Castro, A.M. Formenti, A. Gupta, M.V. Madhavan, N. Nair, V. Babalyan, N.J. Hutchings, N. Napoli, D. Accili, N. Binkley, D.W. Landry, A. Giustina. MECHANISMS IN ENDOCRINOLOGY: vitamin D and COVID-19. Eur. J. Endocrinol. (2020). https://doi.org/10.1530/ EJE-20-0665.

9. A. Giustina, R.A. Adler, N. Binkley, J. Bollerslev, R. Bouillon, B. Dawson-Hughes, P.R. Ebeling, D. Feldman, A.M. Formenti, M. Lazaretti-Castro, C. Marcocci, R. Rizzoli, C.T. Sempos, J.P. Bilezikian, Consensus statement from 2nd International Conference on Controversies in Vitamin D. Rev. Endocr. Metab. Disord. 21(Mar), 89-116 (2020). https://doi.org/10.1007/s11154-019-09532-w. 